\title{
Regulatory Mechanism in Sexual and Asexual Cycles of Dictyostelium
}

\author{
Aiko Amagai \\ Graduate School of Life Sciences, Tohoku University \\ Japan
}

\section{Introduction}

Cellular slime molds exhibit dimorphism in development: sorocarp formation as an asexual cycle and macrocyst formation as a sexual cycle. These two developmental forms are regulated by environmental conditions, such as light and water. Dictyostelium mucoroides 7 (Dm 7), a species of cellular slime molds forms sorocarps in the light, while forming macrocysts in the dark or water (Fig.1).
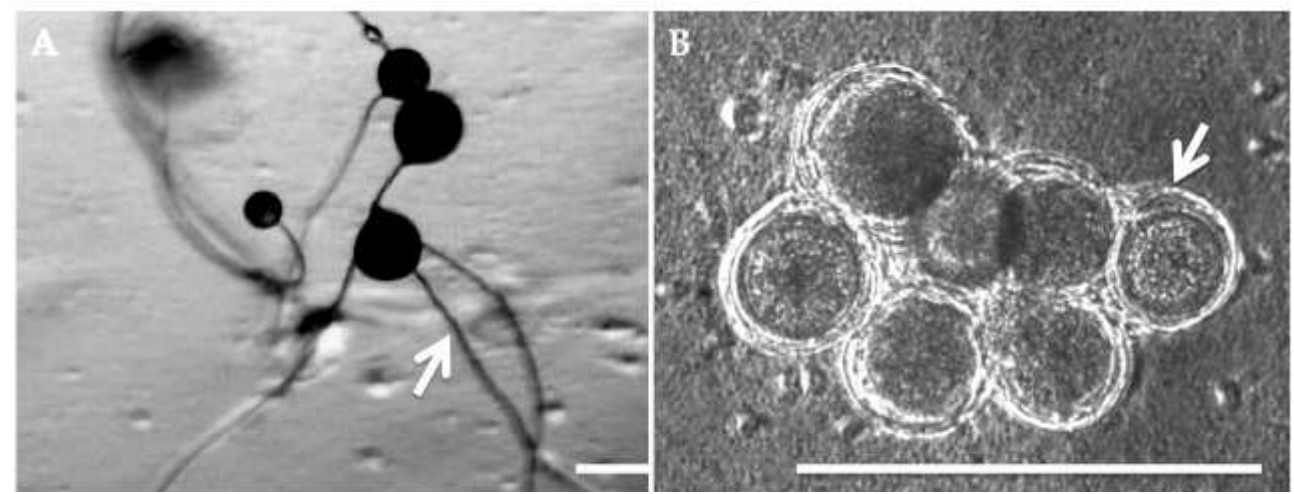

Fig. 1. Two developmental forms in Dm7. A: Starved Dm7 cells were developed on $1.5 \%$ agar in the light. After 48 hours of incubation, they formed sorocarps. A globular spore mass is supported by a stalk (arrow). B: When starved Dm7 cells were developed under submerged conditions, they formed macrocysts. Each macrocyst is surrounded by a thick wall (arrow). Bars: $200 \mu \mathrm{m}$.

In an asexual cycle, amoeboid cells grow and multiply feeding on bacteria. Upon exhaustion of the bacterial food supply (starvation), starving cells stop growing and start the differentiation process. They gather together to form cell aggregates. A tip is formed on the top of each cell aggregate, which then migrates as a slug-shaped mass. After migration, the slug changes its shape dramatically to form a sorocarp consisting of a stalk with an apical mass of spores.

Macrocyst formation as a sexual cycle is characterized by the formation of large aggregates after starvation. Large aggregates are subdivided into smaller masses (precysts), each of 
which is surrounded by a fibrillar sheath. At the center of each precyst, a cytophagic cell (a giant cell) arises, which in turn engulfs all the other cells in the precyst. The engulfed cells (endocytes) are eventually broken down into granular remnants. The enlarged cytophagic cell finally becomes surrounded by a thick wall to form the mature macrocyst (Fig. 2) (Filosa \& Dengler, 1972). After a resting period, the macrocyst germinates to release several amoeboid cells and initiates a new life cycle (Nickerson \& Raper, 1973). Cytophagic cells (giant cells) formed during macrocyst formation have been proved to be zygotes that are produced by cell fusion and subsequent nuclear fusion (Amagai, 1989).
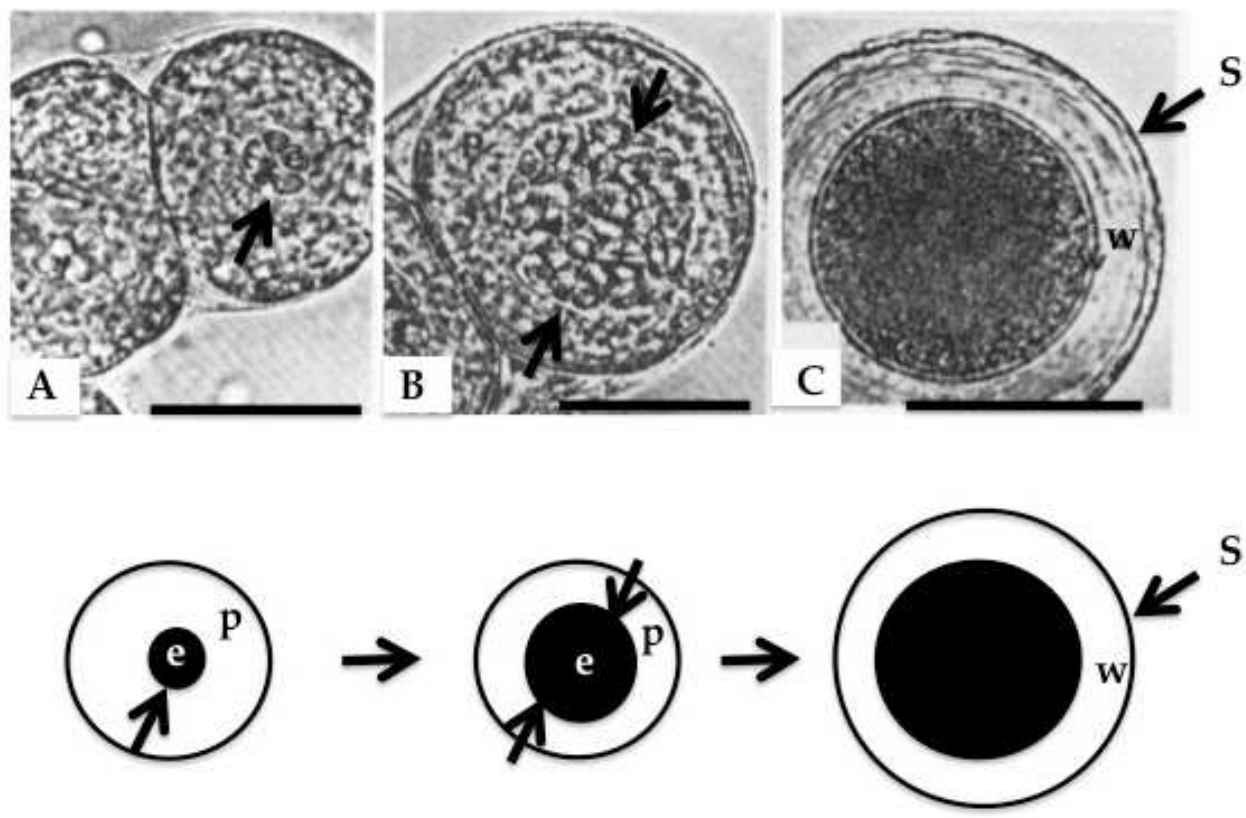

Fig. 2. The developmental process of macrocyst formation. Starved Dm7 cells were developed by shaking. A: 21 hours development after starvation. The first few endocytes have formed at the center of a precyst. A boundary delimits the cluster of endocytes (e) from the surrounding peripheral cells (p) (arrow). B: 24 hours of development. The number of endocytes has increased as more peripheral cells have been engulfed by the cytophagic cell (delimited by arrows). C: 6 day-old cyst filled with granules in Brown motion. After all peripheral cells have been transformed into endocytes, endocytes are broken down into granular remnants. S: fibrillar sheath, W: macrocyst wall. Drawings show the same stages as photographs shown at the top (modified data cited from Filosa \& Dengler, 1972). Bars: $35 \mu \mathrm{m}$.

There are two kinds of mating systems in the macrocyst formation; homothallic and heterothallic (Clark et al., 1973; Erdos et al., 1973). Dm 7 forms macrocysts without mating types as a homothallic strain. On the other hand, Dictyostelium discoideum (D. discoideum), a heterothallic strain, undergoes mating with an opposite mating type, V12M2 cells.

In this chapter, the regulatory mechanism for determining one of two cycles in Dm 7 and $D$. discoideum is reviewed, particularly focusing on the function of ethylene as a potent 
regulator. The signal transduction pathways involved in zygote formation are also noted, specifically paying attention to the function of a novel protein ZYG1, whose expression is augmented by ethylene.

\section{Advantages of using cellular slime molds for cellular and developmental studies}

Cellular slime molds are known as model organisms and have a lot of advantages as materials in the fields of cellular and developmental biology. As the differentiation phase of the cellular slime molds starts by removal of nutrients (starvation), it is temporarily separated from the growth phase. The pattern of cell differentiation is also relatively simple: Dictyostelium cells eventually differentiate into mainly two cell types, spore and stalk cells in an asexual cycle. These characters are quite suitable for studies of differentiation including the mechanisms of the transition from growth to the differentiation phase. As they are usually haploid, it is easier to manipulate genes, such as clone, knockout genes and so on. In fact, many transformants were cloned and used in this chapter. Transformants described here are summarized in Table 1.

\begin{tabular}{|c|c|c|c|}
\hline $\begin{array}{c}\text { Name of } \\
\text { transformants }\end{array}$ & $\begin{array}{l}\text { Organisms } \\
\text { transformed }\end{array}$ & Name of genes & Origin of genes \\
\hline \multicolumn{4}{|l|}{ (Over expression) } \\
\hline ACOOE & $\operatorname{Dm} 7$ & $D d-a c o$ & D. discoideum \\
\hline Dm-ACOOE & $\operatorname{Dm} 7$ & Dm-aco & $\operatorname{Dm} 7$ \\
\hline $\mathrm{OH} 10$ & $\operatorname{Dm} 7$ & $z y g 1$ & $\operatorname{Dm} 7$ \\
\hline $\mathrm{GFP} / \mathrm{ZYG1OE}$ & D. discoideum (Ax2) & $g f p / z y g 1$ & AequoreaVictoria/Dm 7 \\
\hline GFPOE & D. discoideum (Ax2) & $g f p$ & Aequorea victoria \\
\hline HA/ZYG1 & myoblasts (C2C12) & $h a / m z y g 1$ & Influenza virus/Dm 7 \\
\hline \multicolumn{4}{|l|}{ (Under expression) } \\
\hline ACO-RNAi & $\operatorname{Dm} 7$ & $D d-a c o$ & D. discoideum \\
\hline
\end{tabular}

Table 1. Transformants used in this study. $D d-a c o$ : an acc oxidase homologue gene isolated from D. discoideum. Dm-aco : an acc oxidase homologue gene isolated from Dm 7. zyg1: a novel gene isolated from Dm 7. gfp: a green fluorescent protein gene isolated from Aequorea Victoria. gfp/zyg1: a fusion gene of $g f p$ and $z y g 1$. ha/mzyg1: a fusion gene of a hemagglutinin gene $(h a)$ and a humanized zyg1 gene (mzyg1). Introduction of the vector constructs into Dictyostelium cells was performed by electroporation as described by Howard et al. (1988). In case of $\mathrm{C} 2 \mathrm{C} 12$ cells (myoblasts), they were placed on coverslips and transfected with a $h a / m z y g 1$ fusion gene, using Lipofectamine ${ }^{\mathrm{TM}} 2000$ (Invitrogen) according to the manufacturer's instruction. After 6 hours of transfection in Opti-MEM (Invitrogen), samples were washed twice with phosphate buffered saline (PBS) and incubated with Dulbecco's Modified Eagle Medium (DMEM, Invitrogen) containing 10\% fetal bovine serum (FBS) and $80 \mu \mathrm{g} / \mathrm{ml}$ of Kanamycin for $24 \mathrm{~h}$ at $37^{\circ} \mathrm{C}$ in $5 \%$ carbon dioxide $\left(\mathrm{CO}_{2}\right)$ at $95 \%$ humidity. Transformants underexpressing $D d-a c o$ (ACO-RNAi) were obtained by means of the RNAi method. For this purpose, a vector construct of the stem-loop RNA directed against the full length of Dd-aco was infected into Dm 7 cells (Amagai et al., 2007). 


\section{Cyclic AMP and ethylene are potent regulators required for the choice of two life cycles}

\subsection{Identification of ethylene as an inducer of macrocyst formation}

Two life cycles, sorocarp and macrocyst formation, are regulated by several environmental conditions, such as light and water. These environmental conditions affect the synthesis of chemical regulators in cells. The two chemicals, ethylene and cyclic AMP (cAMP), have been demonstrated as regulators for the choice of life cycles in Dm7 (Amagai \& Filosa, 1984; Amagai, 1984). It had already been reported that a volatile substance (CAG) might be involved in the macrocyst formation (Filosa, 1979). Based on the knowledge that the volatile gas is hydrophobic and acts antagonistically to carbon dioxide $\left(\mathrm{CO}_{2}\right)$, ethylene was speculated as a potent candidate of CAG. The possibility that ethylene might act as CAG was tested using MF1 cells, a spontaneous mutant isolated from Dm7. As the mutant MF1 cells are able to form macrocysts even in the light depending upon cell densities plated, the use of MF1 cells makes it easier to analyse results by excluding the factor of light. Considering the effects of cell densities, CAG was suggested to have the threshold concentration to induce macrocyst formation. In fact, MF1 cells failed to form macrocysts even at higher cell densities when they were allowed to develop in a larger incubation chamber. It was supposed that the concentration of CAG produced by the cells would be insufficient for induction of macrocysts by being diluted in the larger chamber. However, MF1 cells changed their developmental forms from sorocarps to macrocysts even in the larger chamber by the addition of ethylene. As was expected, inhibitors of ethylene biosynthesis, such as aminooxyacetic acid (AOA) and aminoethoxyvinyl glycine (AVG) greatly inhibited macrocyst formation. Ethylene production by MF1 and Dm7 cells was confirmed by gas chromatography (Amagai, 1984). From these results, ethylene was concluded to be a CAG, an inducer of macrocyst formation.

\subsection{Determinination of life cycles by the balance of cAMP and ethylene amounts}

Strangely, Dm7 cells formed sorocarps in the light, even though a significant amount of ethylene was produced from them. Why did the Dm7 cells not form macrocysts in the light, though they produced ethylene? This question was resolved by finding cAMP as a negative regulator of macrocyst formation. Developmental fate was actually changed from macrocyst to sorocarp formation in the presence of cAMP (Amagai \& Filosa, 1984). To conclude, it was proposed that the choice of developmental pathways was determined by the balance of cAMP and ethylene amounts at the aggregation stage when developmental fate was determined. This was confirmed by determining the amounts of two regulators produced at the aggregation stage. The amount of cAMP was higher in the sorocarp than in the macrocyst formation, whereas the amount of ethylene production was actually decreased when sorocarps were formed in the presence of AOA (Amagai, 1987).

\subsection{Relation between ethylene amounts and macrocyst formation confirmed using transformants}

The close relationship between the amount of ethylene and the induction of macrocyst formation was confirmed directly, using two kinds of transformants, over- and under- 
producing ethylene (Amagai et al., 2007). Dd-aco, an 1-aminocyclopropane-1-carboxylic acid (ACC) oxidase homologue gene, isolated from $D$. discoideum (DDBJ, EMBL and GenBank databases, accession no. AB105858) was introduced into Dm7 cells to obtain the transformant overproducing ethylene. As ACC oxidase (ACO) catalyzes the last step in the biosynthesis of ethylene, the transformant overexpressing Dd-aco (ACOOE) was expected to increase the production of ethylene (Fig. 3). When the production of ethylene was determined by gas chromatography, ACOOE actually produced a larger amount of ethylene as compared with wild type, Dm7. On the other hand, the transformant underexpressing Dd-aco (ACO-RNAi) which had been isolated by the method of RNAi, produced a smaller amount of ethylene as compared with Dm7. Depending upon the amount of ethylene produced, ACOOE cells formed macrocysts, while ACO-RNAi cells failed to form them, regardless of culture conditions. The relationship between the amount of ethylene produced and the developmental forms in the transformants is summarized in Table 2.

\section{Methionine $\longrightarrow$ SAM $\longrightarrow$ ACC $\longrightarrow$ Ethylene \\ (S-adenosyl-L-methionine) (1-aminocyclopropane- 1-carboxylic acid)}

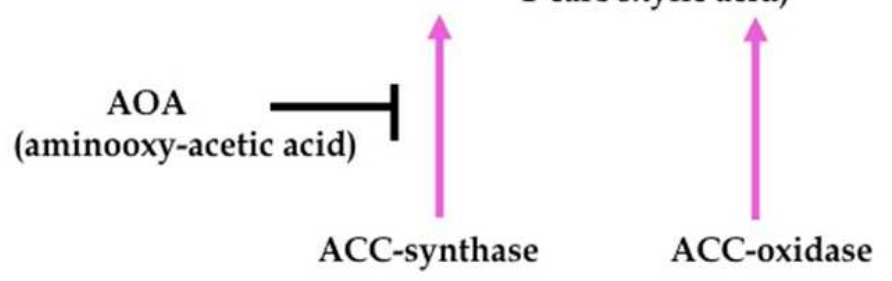

Fig. 3. Ethylene biosynthesis in the cellular slime molds. Ethylene is synthesized from methionine through S-adenosyl-L-methionine (SAM) and 1-aminocyclopropane-1carboxylic acid (ACC) in Dictyostelium as the case in higher plants. ACC synthase catalyzes the production of the ethylene precursor ACC from SAM (S-adenosylmethionine). ACC oxidase catalyzes the last step in the ethylene biosynthesis. AOA (amino-oxy acetic acid) prevents ethylene synthesis by blocking ACC synthase activity.

\subsection{How to induce macrocyt formation by ethylene}

How does ethylene induce macrocyst formation? 1-methylcyclopropene (1-MCP) is known as an inhibitor of ethylene by binding specifically to the cellular ethylene receptors. When starved Dm7 cells were incubated in air containing 224-2,240 ppm of 1$\mathrm{MCP}$, macrocyst formation in the dark was inhibited (Amagai et al., 2007). A family of ethylene receptors such as ETR1 has been first reported as a two-component histidine kinase in Arabidopsis (Bleecker et al., 1988) and then in many kinds of plants such as rice (Goff et al., 2002; Yu et al., 2002), carnation (Shibuya et al., 2002) and tomato (Tieman et al., 2002). Though the ethylene receptors in Dictyostelium have not been identified yet, the effect of MCP suggests the existence of ethylene receptors in Dictyostelium cells. The binding of ethylene with its receptor possibly triggers the signaling pathways leading to macrocyst formation. 


\section{Similarities of ethylene biosynthesis and functions between cellular slime molds and higher plants}

Ethylene is well known to regulate many aspects of the life cycles in plants, including seed germination, root initiation, flower development, fruit ripening, senescence, and responses to several stresses (Abeles et al., 1992). In general, ethylene is synthesized from methionine through S-adenosyl-L-methionine (SAM) and 1-aminocyclopropane-1-carbo-xylic acid(ACC) (Adams \& Yang, 1979). It has been suggested that ethylene may be biosynthesized in Dictyostelium cells through the same pathway as that in plants (Fig.3) (Amagai \& Maeda, 1992). In fact, Dictyostelium homologue genes of ACC synthase (Dd-acs) and ACC oxidase $(D d-a c o)$ have been isolated from $D$. discoideum by the Japanese Dictyostelium cDNA project and the genome project of Dictyostelium (Eichinger et al., 2005). The ACC oxidase homologue gene was also isolated from Dm7 (Dm-aco) (DDBJ, EMBL and GenBank databases, accession no. AB291210). When the nucleotide sequence of Dm-aco is compared with that of $D d$-aco, only one nucleotide, thymidine at $672^{\text {nd }}$ in $D d$-aco is replaced with cytosine in Dm-aco. The deduced amino acid sequences encoded by the two genes are completely identical (Amagai et al., 2007). Dd-ACO shows $24.3 \%$ of identity and $40.0 \%$ of similarity, in comparison with the ACC-oxidase of Arabidopsis (accession number

\begin{tabular}{|c|c|c|c|c|}
\hline \multirow{2}{*}{ Cells } & \multirow{2}{*}{$\begin{array}{c}\text { The amounts of } \\
\text { ethylene } \\
\text { production (\%) }\end{array}$} & \multicolumn{2}{|c|}{ Developmental forms } & \multirow{2}{*}{ zygote formation } \\
\cline { 3 - 4 } & 100 & light & dark & \\
\hline Dm 7 & 167 & SC & MC & + \\
\hline ACOOE & 183.9 & MC & MC & nd \\
\hline Dm-ACOOE & 82.7 & nd & nd & ++ \\
\hline ACO-RNAi & SC & SC & - \\
\hline
\end{tabular}

Table 2. The relation of ethylene production to developmental forms. The determination of ethylene production from Dm7 and transformants was performed by gas chromatography. The amounts of ethylene produced from transformants are shown as relative values to that from Dm7 cells. Developmental forms: Starved cells were plated separately at $5 \times 10^{5}$ cells $/ \mathrm{cm}^{2}$ on agar in a glass dish (diameter: $3.5 \mathrm{~cm}$ ) and incubated at $22^{\circ} \mathrm{C}$ either in the light or in the dark. After 48 hours of incubation, Dm 7 cells form sorocarps in the light and macrocysts in the dark (See Fig.1). ACOOE cells form macrocysts even in the light. ACORNAi cells form sorocarps in the light. Even in the dark, ACO-RNAi cells form tiny sorocarps and loose aggregates instead of macrocysts (Amagai et al., 2007). Zygote formation: Dm7 and a transformant overexpressing Dm-aco (Dm-ACOOE) were developed by shaking for 1.5 hours after starvation, fixed with methanol, and stained with DAPI. The binucleate cells caused by cell fusion were formed in Dm 7 cells. On the other hand, in Dm$\mathrm{ACO}$, huge cells containing a large number of nuclei were frequently formed due to the enhanced cell fusion (Amagai, 2011) (See Fig.5). When ACO-RNAi cells were developed under the submerged conditions and stained with DAPI, such binucleate cells were scarcely formed (Amagai et al, 2007). SC: sorocarp, MC: macrocyst, nd: not determined. The number of "+", the degree of zygote formation: "- ", no zygote formation. 
AAC27484). These are not high. However, by the Pfam homology search, Dd-ACO was found to contain a conserved 2-oxoglutalate (2OG) and Fe (II) dependent oxygenase superfamily domain (210-307th amino acids from the initiation site), which is characteristic of enzymes catalyzing oxidation of the organic substrate such as ACC. It also contained two histidine sites at 229th and 287th for binding iron which are necessary for activation of the enzyme (Aravind \& Koonin, 2001). Determining the ethylene production by gas chromatography, it was confirmed that ethylene was actually biosynthesized by Dd-aco and Dm-aco (Table 2) (Amagai et al., 2007; Amagai, 2011). In addition, it is important to note the existence of ethylene receptor(s) in Dictyostelium cells as suggested before (Amagai et al., 2007). Taken together, these results suggest high similarities in the biosynthetic pathway and functions of ethylene between higher plants and Dictyostelium. Therefore, the study using Dictyostelium will contribute to obtaining new insights into the functions of ethylene beyond species.

\section{Two chemicals regulate zygote formation at cellular level}

\subsection{Determination of developmental stages requiring ethylene for macrocyst formation}

There are several cellular events occurring in the process of macrocyst formation, such as zygote formation and engulfment of the other cells by a zygote in a precyst, etc. Which events are controlled by ethylene? In order to determine the developmental stages when ethylene is effective to induce macrocyst formation, ethylene gas produced by Dm7 and MF1 cultures was removed by the use of charcoal at various stages in development. As a result, the developmental fate was shifted from macrocyst to sorocarp formation by removal of ethylene at the early developmental stages. This means that ethylene is necessary for macrocyst formation at the early stages of development. However, ethylene becomes unnecessary for macrocyst formation at the later stages of development. The timing when ethylene becomes unnecessary for macrocyst formation is consistent with the timing of the appearance of binucleate cells. When cells were stained with 4'-6-diamidino2-phenylindole (DAPI), binucleate cells formed by cell fusion were recognized. The appearance of zygotes during development was determined by counting the number of binucleate cells as a marker of zygotes. As a result, binucleate cells were noticed at the aggregation stage (Fig. 4).

\subsection{Control of zygote formation by two regulators}

The developmental time requiring non-necessity of ethylene for macrocyst formation was delayed due to below the threshold concentration of ethylene when the cell densities plated were lowered. However, when ethylene was applied in the culture dishes at the beginning of this culture, the time requiring non-necessity of ethylene for macrocyst formation was advanced in concert with the advanced and increased formation of binucleate cells (Amagai, 1989). These results strongly suggest that ethylene may directly induce zygote formation. As was expected, cAMP, the second regulator, exhibits an inhibitory effect on the process of zygote formation (Suzuki et al., 1992). When the number of binucleate cells stained with DAPI was counted, the number was decreased by the addition of CAMP, while it was increased by the addition of phosphodiesterase (PDE), which hydrolyzed cAMP to 5' AMP. In conclusion, two regulators, ethylene and cAMP, directly regulate zygote formation. 


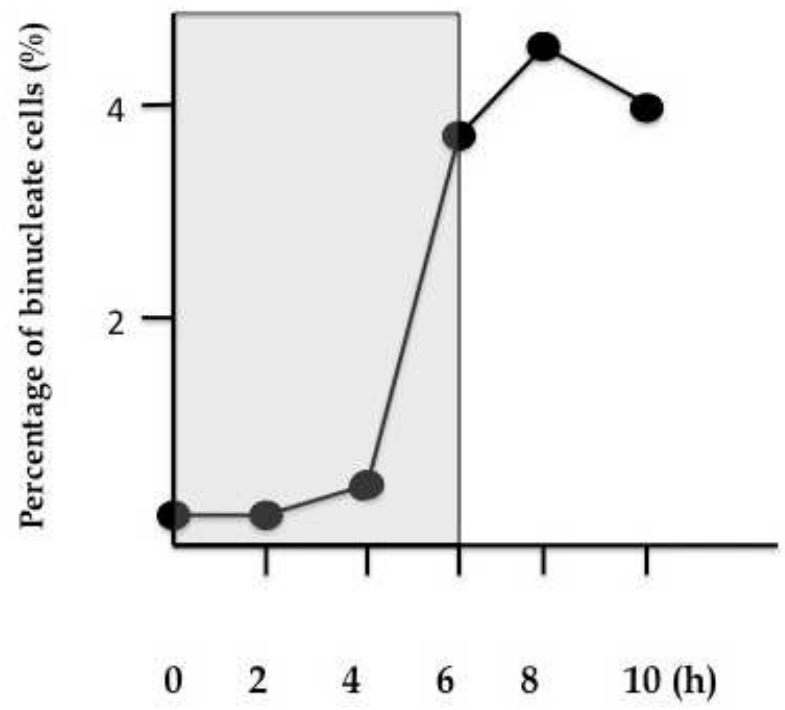

Fig. 4. The formation of binucleate cells during macrocyst formation in Dm7 cells. Starved Dm7 cells at $1 \times 10^{6}$ cells $/ \mathrm{cm}^{2}$ were allowed to develop for 2 hours at $22^{\circ} \mathrm{C}$ in the dark, transferred to $4^{\circ} \mathrm{C}$ and kept overnight. Subsequently, the temperature was again shifted from $4^{\circ} \mathrm{C}$ to $22^{\circ} \mathrm{C}$ and incubated for the designated hours (h). This was followed by fixation with methanol and staining with DAPI. The percentages of binucleate cells were determined by counting the number of cells under a fluorescence microscope using UV excitation. Cell aggregates are formed at 6 hours, and subdivided into smaller cell masses at 10 hours. Each of the cell masses eventually develops to macrocysts. The low temperature treatment was performed to synchronize cellular development. The periods during which ethylene is necessary for macrocyst formation are shown by a grey zone. The timing when ethylene becomes unnecessary for macrocyst formation is consistent with the timing of the appearance of binucleate cells (basically from Amagai, 1989).

\subsection{Relation between ethylene amounts and zygote formation confirmed using transformants}

The close relationship between the amount of ethylene produced and zygote formation was also shown clearly using two types of transformants: Cells overexpressing Dm-aco (DmACOOE) formed huge cells containing a large number of nuclei as a result of enhanced cell fusion (Fig. 5), accompanying the expression of Dm-aco mRNA and the larger amount of ethylene production as compared with Dm 7 (Table 2) (Amagai, 2011). In contrast, ACORNAi cells never formed zygotes as was expected (Table 2) (Amagai et al., 2007). In heterothallic strains, zygote formation is also regulated by ethylene and cAMP. It was induced by ethylene, while it was inhibited by cAMP (Amagai, 1992; O'Day \& Lydan, 1989). Incidentally, D. discoideum and its mating type, V12M2 cells also produce ethylene (Amagai \& Maeda, 1992). Accordingly, ethylene and cAMP may act on the regulation of zygote formation beyond the difference of mating systems. Ethylene functions in other cellular events occurring during macrocyst formation remain to be elucidated. 
Besides ethylene and cAMP, $\mathrm{Ca}^{2+}$ has been shown to induce zygote formation. That is, the percentage of zygotes was elevated by the presence of extracellular $\mathrm{Ca}^{2+}$ in $D$. discoideum and Dm 7 and by the increase of intracellular $\mathrm{Ca}^{2+}$ in D. discoideum (Chagla et al., 1980; Lydan \& O'Day, 1988a; Suzuki et al., 1992; Szabo et al.,1982).
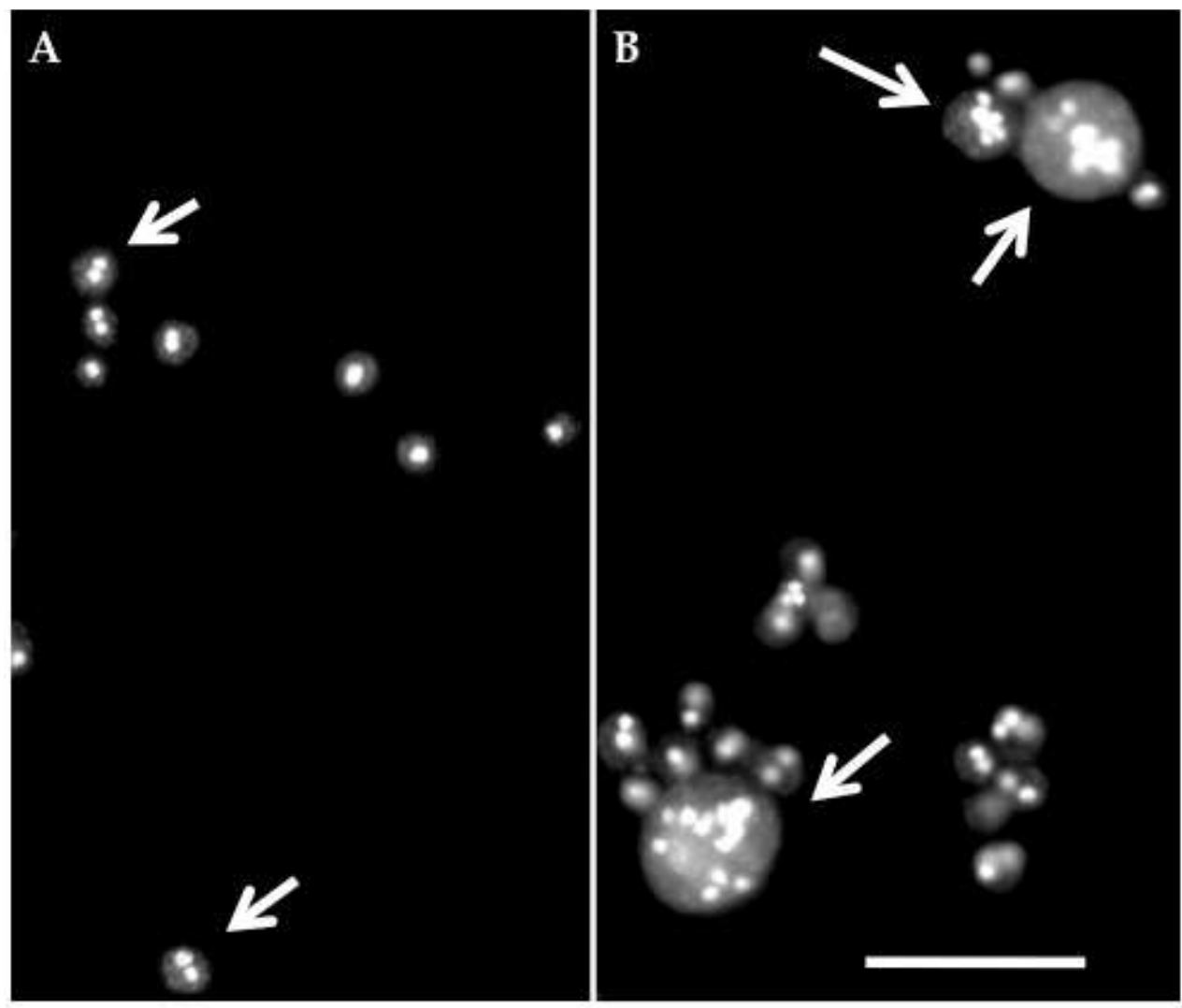

Fig. 5. Induction of multinucleate giant cells by enforced expression of the Dm-aco gene and the larger amount of ethylene production. Dm7 and their transformant overexpressing Dmaco (Dm-ACOOE) were developed separately by shaking for 1.5 hours after starvation, fixed with methanol and stained with DAPI. Some binucleate cells (arrows) caused by cell fusion are observed in Dm 7 cells (A). In Dm-ACOOE cells (B), huge cells containing multi-nuclei are formed, indicating that cell fusion is markedly enhanced (Amagai, 2011). Bar: $50 \mu \mathrm{m}$.

\section{Ethylene induces the expression of a novel gene, zyg1}

\subsection{Description of zyg1}

As a gene involved in zygote formation, a novel gene zyg1 cDNA (DDBJ/EMBL/ GenBank, accession no. AB006956) expressed predominantly during macrocyst formation was isolated by the differential screening method (Amagai, 2002). The zyg1 gene was isolated also from 
genomic DNA of Dm7 and D. discoideum (Ax2) cells by PCR and sequenced (accession number: AB479506 for Dm-zyg1, AB479507 for Dd-zyg1). The comparison of sequences of zyg1 between genomic DNA of Dm7 and Ax2 cells shows 100\% identity besides the existence of intron (578-648) in Dm7 genome (in preparation). The predicted protein, ZYG1, consists of 268 amino acids with a molecular mass of $29.4 \mathrm{kDa}$. After BLAST (Altschul et al., 1990) and FASTA (Pearson, 1990) searches, the amino acid sequence as a whole shows no convincing similarity to known proteins. Although the ZYG1 protein is predicted to have several sites phosphorylated by protein kinase $C$ (PKC), it has neither transmembrane domains nor specific signal sequences (Fig. 6). The expression of the zyg1 gene began 2 hours after starvation, reached maximum level at 8 hours, and then decreased, when Dm7 cells were cultured under submerged conditions (Amagai, 2002). Such an expression pattern is quite similar to the developmental kinetics of zygote formation with about 1 hour precedence. The number of zygotes began to increase 5 hours after starvation, reached the maximum level at 9 hours and then gradually decreased (Kawai et al., 1993). From these observations, the zyg1 gene was predicted to be closely involved in zygote formation. As was expected, a transformant overexpressing a zyg1 gene $(\mathrm{OH} 10)$ was found to form macrocysts on agar even in the light. In addition, they formed a number of zygotic giant cells besides macrocysts. These results suggested that the zyg1 gene might be involved in the induction of zygote formation (Amagai, 2002).

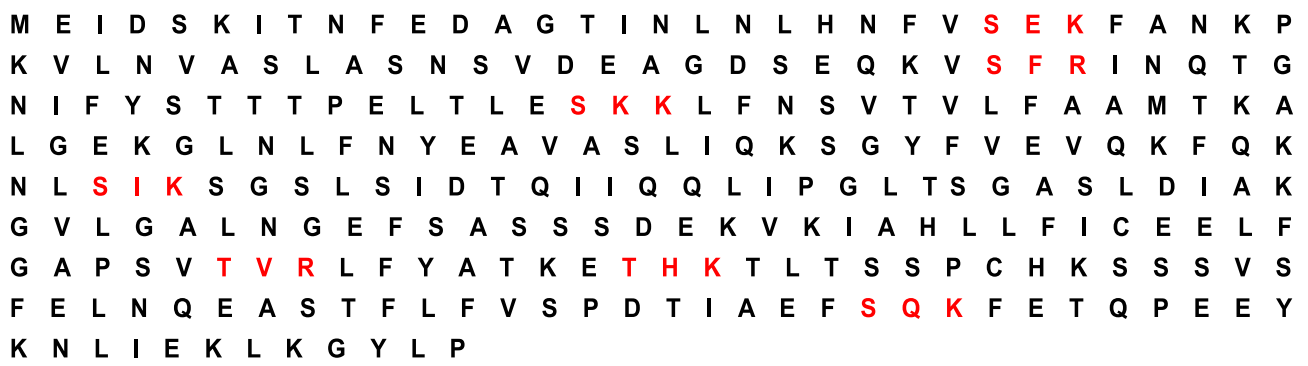

Fig. 6 . The predicted amino acid sequence of ZYG1. The nucleotide sequence of $z y g 1$ is deposited in the DDBJ, EMBL and GenBank databases with the accession number AB06956. Amino acid sequences of ZYG1 shown as red color indicate the position of predicted PKCphosphorylation sites (Amagai, 2002).

\subsection{Relation between ethylene and zyg1}

It is quite possible that the action of ethylene may be realized through an enhanced ZYG1 expression. In order to examine this possibility, the expression of the zyg1 gene during development was examined and compared, using two kinds of transformants, $\mathrm{ACOOE}$ and ACO-RNAi. Depending upon ethylene production, Dm7 cells and ACOOE cells exhibited higher levels of zyg1 expression, while ACO-RNAi cells had a significantly lower level of $z y g 1$ expression. Incidentally, the zyg1 expression was decreased by application of AOA, an inhibitor of ethylene biosynthesis (Fig. 7). From this, it was certified that the expression of zyg1 was induced by ethylene. However, the mechanism of how ethylene induces zyg1 expression has not been resolved yet. Taken together these results indicate that ethylene induces zygote formation through an enhanced expression of zyg1 (Amagai et al., 2007). 
A

\section{Zyg1mRNA rRNAs}

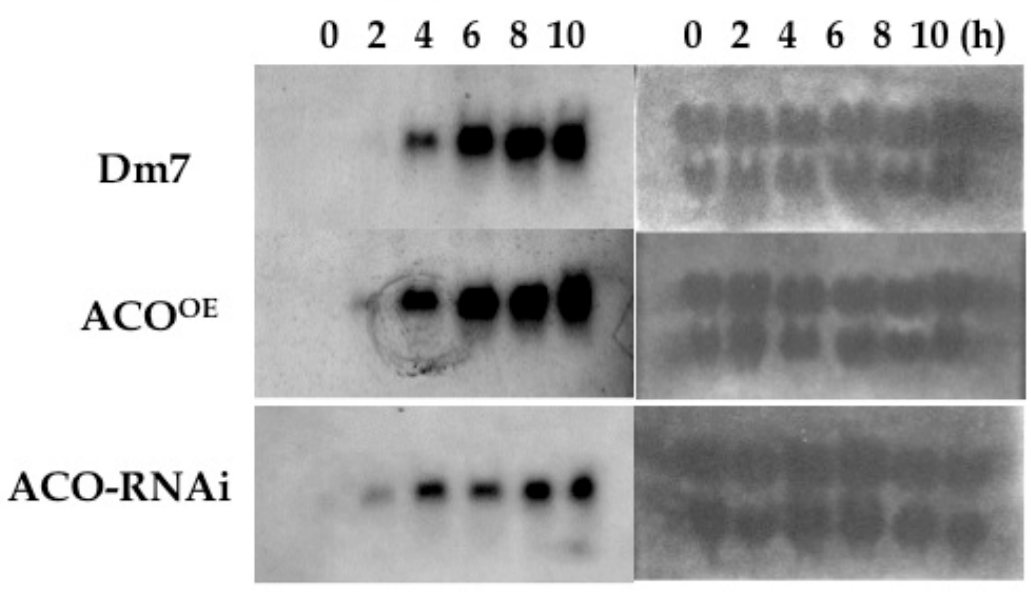

B

\section{AOA concentration (mM)}

\section{Zyg1mRNA rRNAs}

$\begin{array}{llllll}0 & 2.5 & 5 & 0 & 2.5 & 5\end{array}$

Fig. 7. A. Expression patterns of zyg1 in Dm7, ACOOE and ACO-RNAi cells during development. Starved Dm7, ACOOE and ACO-RNAi cells were placed at $5 \times 10^{5} \mathrm{cells} / \mathrm{cm}^{2}$ in glass dishes (diameter: $9 \mathrm{~cm}$ ) and developed under submerged conditions (Bonner's salt solution), respectively. Total RNAs were extracted at 2 hours intervals during development. $30 \mu \mathrm{g}$ of total RNA was loaded on each lane, electrophoresed and transferred to membranes. The expression of $z y g 1$ was detected using the full length of $z y g 1 \mathrm{cDNA}$ as a probe. The membranes were exposed on X-ray films for a week. The large (26S) and small (17S) subunits of ribosomal RNAs blotted on the membranes are shown as loading controls in the right panels. It is clear that zyg1 mRNA is expressed earlier in ACOOE cells than in Dm7 cells, but that zyg1 expression is significantly suppressed in ACO-RNAi cells. B. Effect of AOA on zyg1 expression. Starved Dm7 cells were placed at $1 \times 10^{6}$ cells $/ \mathrm{cm}^{2}$ in glass dishes (diameter: $3.5 \mathrm{~cm}$ ) under the submerged conditions (20 mM MES, pH 7.0). Subsequently, the indicated concentrations (final concentrations) of AOA were added to culture dishes, respectively. After 8 hours of incubation, total RNAs were extracted from cells. $12.6 \mu \mathrm{g}$ of total RNA was loaded on each lane and probed using the full length of zyg $1 \mathrm{cDNA}$, as described above. The membranes were exposed on X-ray films for 1 day. It is evident that zyg1 expression is decreased by AOA in a dose-dependent manner. The large (26S) and small (17S) subunits of ribosomal RNAs stained with EtBr are shown as loading controls in the right panel. These results indicate that ethylene induces the expression of $z y g 1$ (cited from Amagai et al., 2007). 


\section{The possible mechanisms of zygote induction by ethylene}

As described above, ethylene, zyg1, $\mathrm{Ca}^{2+}$, and cAMP regulate zygote formation. How are these regulators involved in signal transduction pathways for zygote formation? There are inductive and inhibitory signal transduction pathways for zygote formation. Inductive signal transduction pathways are described first, and inhibitory signal transduction pathways next.

\subsection{Inductive signal transduction pathways for zygote formation}

Intracellular $\mathrm{Ca}^{2+}$ binds to calmodulin and PKC. $\mathrm{Ca}^{2+}$-calmodulin complex binds the target proteins, acting positively on zygote formation (Lydan \& O'Day, 1988b). Concerning PKC, phorbol esters such as 12O-tetradecanoylphorbol-13-acetate (TPA), potent activators of PKC, have been reported to enhance the formation of zygotes in both D. discoideum and Dm 7 . In contrast, staurosporine, an inhibitor of protein kinases including PKC, inhibited zygote formation in both D. discoideum and Dm 7 (Amagai, 2011; Gunther et al., 1995) and macrocyst formation in Dm7 (Kawai et al., 1993). From these results, PKC activated by the increase of intracellular $\mathrm{Ca}^{2+}$ possibly participates in the induction of zygote formation. However, the target substrate of PKC had not been identified. Since ZYG1 has several predicted sites phosphorylated by PKC, ZYG1 was a likely candidate for the substrate of PKC. Therefore, whether ZYG1 was phosphrylated by PKC or not was examined, using a transformant overexpressing a $g f p / z y g 1$ fusion gene. The localization of ZYG1 was monitored by GFP, and phosphorylation of ZYG1 was detected by the anti-phosphoserine antibody which specifically recognized serine residues phosphorylated by PKC and then the Rhodamine conjugated secondary anti-rabbit IgG antibody. When the green color of GFP (GFP/ZYG1 fusion protein) was merged with the red color of Rhodamine (proteins phosphorylated by cPKC), the color changed to yellow in GFP/ZYG1OE cells at the regions of cell-to-cell contacts (Fig. 8H, arrow). This showed that GFP/ZYG1 fusion protein was colocalized with the proteins phosphorylated by cPKC there. Since the co-localization of GFP and the protein phosphrylated by PKC was not observed in GFPCONT cells (Fig. 8G, arrow), the localization of ZYG1 at the region of cell-to cell contact was shown clearly (Amagai et al., 2012). This suggests a strong implication of ZYG1 phosphorylated by PKC in zygote formation. However, the phorphorylated sites of ZYG1 protein have not been identified yet.

\subsection{Inhibitory signal transduction pathways for zygote formation}

Inhibitory signal transduction pathways are described next. As 2'-deoxy-cAMP (a cAMP analog) with a high affinity for the surface cAMP receptor inhibited zygote formation, it was suggested that cAMP operates by binding to a surface receptor to mediate downstream signaling events (Suzuki et al., 1992). The inhibitory effect of cAMP on zygote formation was nullified, when K252a, a potent inhibitor of protein kinases (PKA, PKC, and PKG) was coapplied with cAMP. In addition, when KT5720 (a specific inhibitor of PKA) and W7 (calmodulin inhibitor) were co-applied, zygote formation was enhanced (Kawai et al., 1993). From these results, it is evident that the activation of PKA triggered by binding cAMP with its receptor and calmodulin dependent protein kinase are involved in the inhibition of zygote formation. However, target proteins for PKA and calmodulin dependent protein kinase presently remain to be identified. Since these protein kinase inhibitors are effective at the developmental stage when the cells acquired fusion competence, it is most likely that they may inhibit the process of gamete formation. In this way, calmodulin dependent protein kinases are involved in both inductive and inhibitory signal transduction pathways 
(Lydan \& O'Day, 1988b). The inductive and inhibitory signal transduction pathways involved in zygote formation are summarized in Fig. 9.
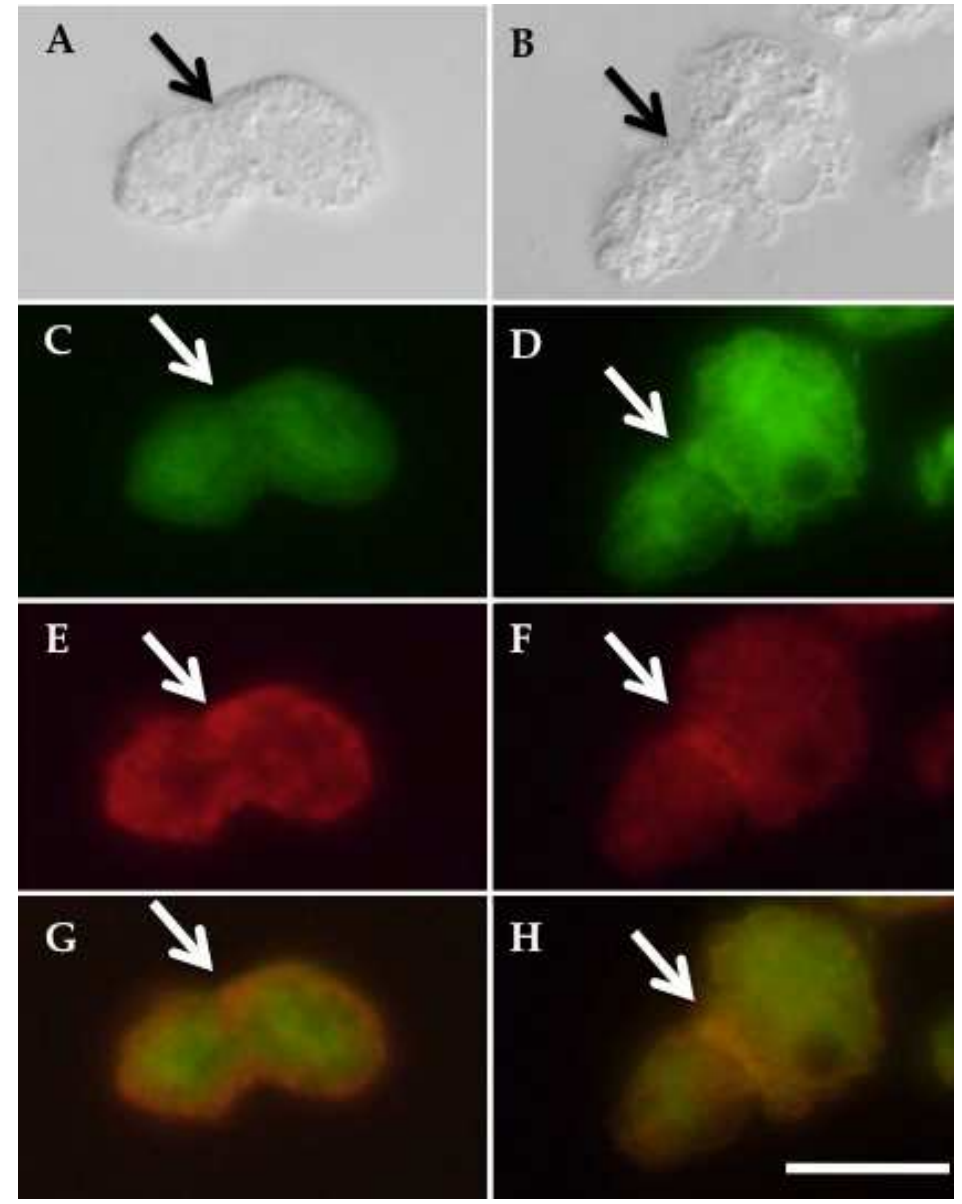

Fig. 8. Immunocytochemical detection of the PKC-mediated ZYG1 phosphorylation. Starved GFPCONT and GFP/ZYG1OE cells were developed for $2 \mathrm{~h}$, fixed with $4 \%$ paraformaldehyde and stained by the Phospho-(Ser) PKC Substrate antibody. This was followed by the rhodamineconjugated anti-rabbit secondary antibody to detect the proteins phosphorylated by cPKC. Photographs were taken under DIC (A and B) and fluorescence microscopes (GFP, C and D; Rhodamine, E and F; GFP and Rhodamine merged, $G$ and $H)$. Photographs represent the same fields of GFPOE cells (A, C, E, G) and of GFP/ZYG1OE cells (B, D, F, H). In GFP/ZYG1OE cells, the green color of GFP (GFP/ZYG1 fusion protein) merged with the red color of Rhodamine (proteins phosphorylated by $\mathrm{cPKC}$ ) shows yellow color at the region of cell-to-cell contacts $(\mathrm{H}$, arrow). This shows that GFP/ZYG1 and the protein phosphorylated by PKC are co-localized particularly there. While, in GFPCONT cells, the co-localization of GFP and the protein phosphorylated by PKC is not observed (G, arrow). This shows that ZYG1 itself is located at the region of cell-to-cell contact and phosphorylated by PKC (Amagai et al., 2012). Bar, $25 \mu \mathrm{m}$. 


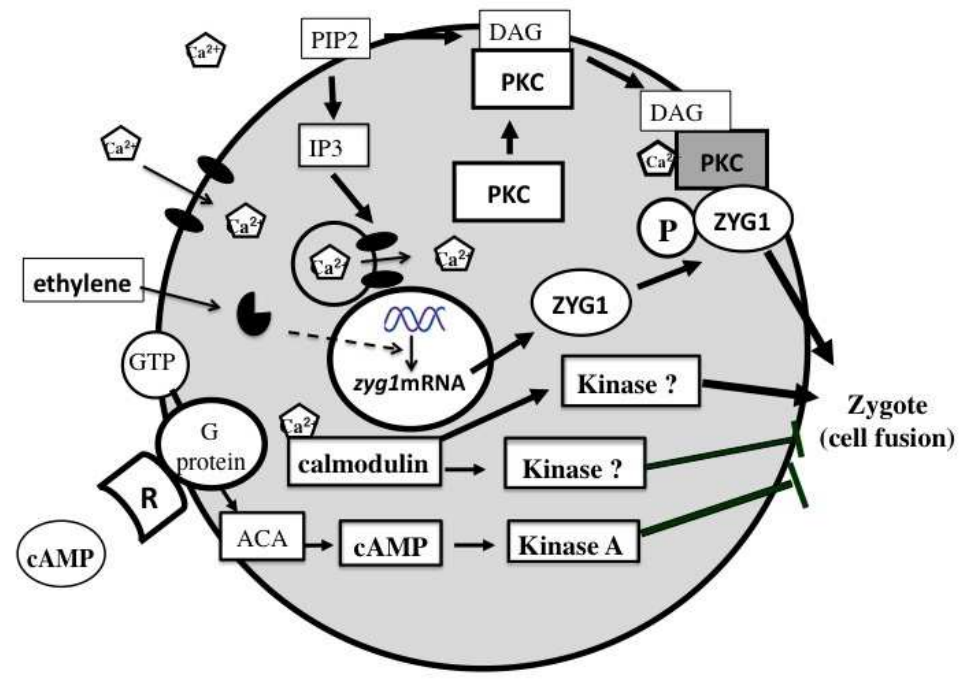

Fig. 9. Schematic representation of the proposed signal transduction pathways for the induction and inhibition of sexual cell fusion (zygote formation). The binding ethylene with its receptor ( $)$ ) and the increase of intracellular calcium begin the inductive signal transduction pathway. The increase of intracellular $\mathrm{Ca}^{2+}$ activates PKC (gray color shows activated PKC). Ethylene induces the expression of zyg1. ZYG1 phosphorylated by activated PKC causes cell fusion. For the inhibition of zygote formation, cAMP binds to its receptor (R) and then activates PKA. Calmodulin dependent protein kinases are involved in both inductive and inhibitory signal transduction pathways. GTP, guanosine-5'-triphosphate; PIP2, phosphatidylinositol 4,5-bisphosphate; IP3, inositol triphosphate; DAG, diacylglycerol. $\rightarrow$ : induction; $\perp$ : inhibition.

\subsection{Induction of myoblast fusion by zyg1}

$\mathrm{Ca}^{2+}$-and PKC- mediated signal transduction pathways are known to be involved in myoblast fusion during myogenesis (David et al., 1990; Paterson \& Strohman, 1972; Shainberg et al., 1969). Therefore, it is possible that there may be common signal transduction pathways for cell fusion between myoblasts and Dictyostelium cells. To test this possibility, a humanized version of the zyg1 gene (mzyg1) was synthesized in which each amino acid codon was replaced by that most commonly found in mammalian cells (DNA 2.0 Inc.). The construct containing a fusion gene of $h a$ and mzyg1 (ha/mzyg1) was introduced into mouse C2C12 cells. At 24 hours of incubation after transfection, cells were fixed with $4 \%$ paraformaldehyde, followed by immunostaining with the anti-HA antibody (mouse) and then the FITC-conjugated secondary anti-mouse IgG antibody. Their nuclei were stained with DAPI. As a result, cells expressing the HA/ZYG1 fusion protein (HA/ZYG1) were recognized as the green color of FITC. Quite interestingly, green colored cells expressing the HA/ZYG1 fusion protein were found to form giant multinucleate cells frequently (Fig.10). They exhibited fibroblast-like morphology. However, the highly elongated cells as observed during typical myoblast fusion, in which nuclei were arranged in a single file, were not observed. Though the cell shape was different from normal multinucleate cells in myotube, 
it is clear that cell fusion is actually induced by ZYG protein (Amagai et al., 2012). Since ZYG1 has not a mammalian ortholog, ZYG1 could take place of the protein phosphorylated by PKC in mammal cells. It is supposed that the protein phosphorylated by PKC during myoblast fusion might be functionally similar, though the target protein of PKC in myoblasts has not been identified yet.

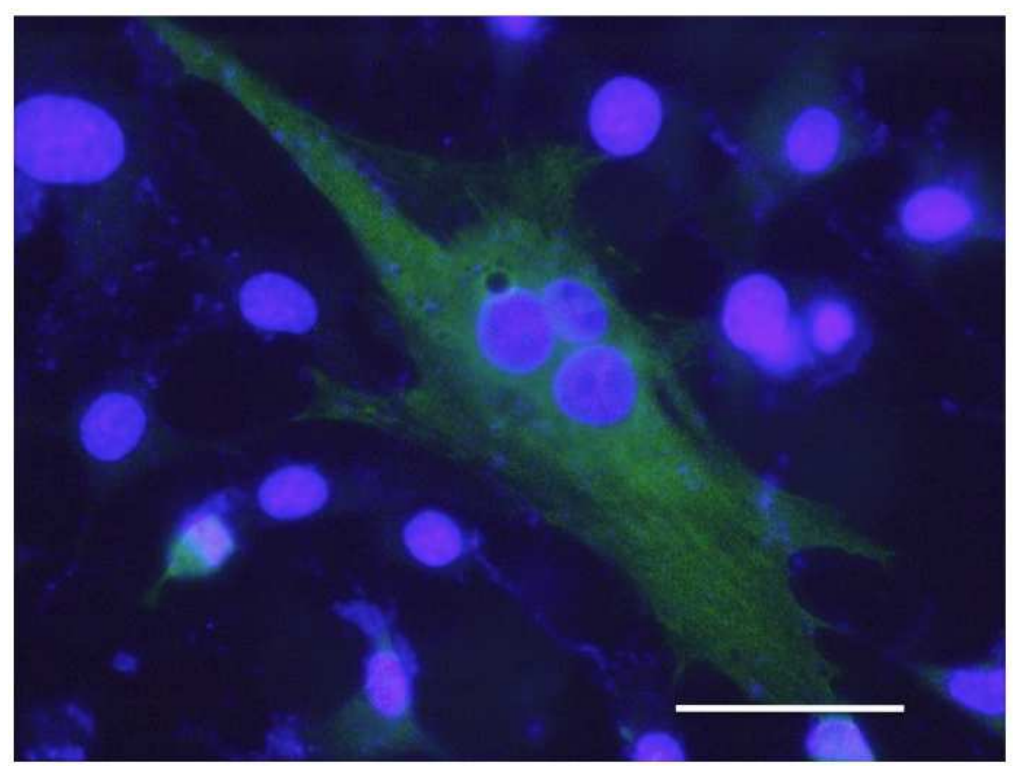

Fig. 10. Formation of multinucleate cells in mouse $\mathrm{C} 2 \mathrm{C} 12$ cells transfected with a ha/mzyg1 fusion gene. C2C12 cells were transfected with a ha/mzyg1 fusion gene. After 24 hours of incubation, cells were fixed with $4 \%$ paraformaldehyde, followed by immunostaining with the anti-HA antibody (mouse) and then the FITC-conjugated secondary anti-mouse IgG antibody. The samples were also stained with DAPI. The photograph shows a FITC image merged with a DAPI image under a fluorescence microscope. A cell expressing HA/ZYG1 fusion protein shows the green color of FITC. Nuclei show the purple color of DAPI. Since a large-sized green cell expressing HA/ZYG1 contains three nuclei, it is most likely that cell fusion may be induced by ZYG1. mzyg1: a humanized version of the zyg1 gene (cited from Amagai et al., 2012). Bar, $50 \mu \mathrm{m}$.

\section{Conclusion}

It is evident that the regulatory mechanisms to determine the reproduction cycles are common between homothallic and heterothallic strains, regardless of different mating systems. Ethylene induces macrocyst formation as a sexual cycle, while cAMP induces sorocarp formation as an asexual cycle. At the cellular level, ethylene induces zygote formation, which is formed by cell fusion and subsequent nuclear fusion during macrocyst formation, through an enhanced expression of a novel gene, zyg1. ZYG1 may be a likely substrate for PKC in the pathway of $\mathrm{Ca}^{2+}$-and PKC- mediated signal transduction. Inversely, cAMP inhibits zygote formation, possibly through a PKA-related signaling 
pathway. In this chapter, the functions of ethylene in macrocyst formation have been proved at the levels of individuality (macrocyst formation), cell (zygote formation), and molecule (zyg1 expression). It is of interest to note that the enforced expression of ZYG1 induces cell fusion in myoblast as well as in Dictyostelium cells. Thus the data presented here must give us a principal insight into the mechanisms of developmental regulation in a wide range of organisms including Dictyostelium. The functions of ethylene and ZYG1 in the cell fusion process will be particularly memorable.

\section{Acknowledgment}

I am grateful to Prof. Yasuo Maeda (Tohoku University) and Prof. Michael MacManus (Miyagi University of Education) for their critical reading and insightful comments of the manuscript. I would like to thank Dr. Michael F. Filosa, and all people who support these works.

\section{References}

Abeles, F. B., Morgan, P. W., Saltveit, M. E. J. (1992). Ethylene in plant biology, 2nd (ed.), New York: Academic Press.

Adams, D. O. \& Yang, S. F. (1979). Ethylene biosynthesis: identification of 1aminocyclopropane-1-carboxylic acid as an intermediate in the conversion of methionine, Pro.Natl. Acad. Sci. USA 76: 170-174.

Altschul, S. F., Gish, W., Miller, W., Myers, E. W. \& Lipman, D. J. (1990). Basic local alignment search tool, J Mol Biol 215: 403-10.

Amagai, A. (1984). Induction by ethylene of macrocyst formation in the cellular slime mould Dictyostelium mucoroides, J Gen Microbiol 130: 2961-2965.

Amagai, A. \& Filosa, M. F. (1984). The possible involvement of cyclic AMP and volatile substance(s) in the development of a macrocyst-forming strain of Dictyostelium mucoroides, Dev Growth Differ 26: 583-589.

Amagai, A. (1987). Regulation of the developmental modes in Dictyostelium mucoroides by cAMP and ethylene, Differentiation 36: 111-115.

Amagai, A. (1989). Induction of zygote formation by ethylene during the sexual development of the cellular slime mold Dictyostelium mucoroides, Differentiation 41: 176-183.

Amagai, A., Soramoto, S., Saito, S. \& Maeda, Y. (2007). Ethylene induces zygote formation through an enhanced expression of zyg1 in Dictyostelium mucoroides, Exp Cell Res 313: 2493-2503.

Amagai A. (1992). Induction of heterothallic and homothallic zygotes in Dictyostelium discoideum by ethylene, Dev Growth Differ 34: 293-299.

Amagai, A. \& Maeda Y. (1992). The ethylene action in the development of cellular slime molds: an analogy to higher plants, Protoplasma 167: 159-168.

Amagai A. (2002). Involvement of a novel gene, zyg1, in zygote formation of Dityostelium mucoroides, J Muscle Res Cell Motility 23: 867-74.

Amagai, A. (2011). Ethylene as a potent inducer of sexual development, Dev Growth Differ 53: 617-623,

Amagai, A., MacWilliams, H., Isono, T., Omatsu-Kanbe, M., Urano, S., Yamamoto, K. \& Maeda, Y. (2012). PKC-mediated ZYG1 phosphorylation induces fusion of myoblasts as well as of Dictyostelium cells, Int J Cell Biol 2012: 11 pages, ArticleID 657423, doi:10.1155/2012/657423 
Aravind, L. \& Koonin, E. V. (2001). The DNA-repair protein AlkB, EGL-9, and leprecan define new families of 2-oxoglutarete- and iron-dependent dioxygenases, Genome Biol 2: research0007.

Bleecker, A. B., Estelle, M. A.. Somerville, C. \& Kende, H. (1988). Insensitivity to ethylene conferred by a dominant mutation in Arabidopsis thaliana, Science 241: 1086-1089.

Brefeld, O. (1869) Dictyostelium mucoroides. Ein neuer Organismus aus der Verwandshaft der Myxomyceten. Abhandl. Senckenbergish Naturf. Ges 7: 85-107.

Chagla, A. H., Lewis, K. E. \& O'Day, D. H. (1980). $\mathrm{Ca}^{2+}$ and cell fusion during sexual development in liquid cultures of Dictyostelium discoideum, Exp Cell Res 126: 501-505.

Clark, M. A., Francis, D. \& Eisenberg, R. (1973). Mating types in cellular slime molds, Biochem Biophys Res Com 52: 672-678.

David, J. D., Faser, C. R. \& Perrot, G. P. (1990). Role of protein kinase C in chick embryo skeletal myoblast fusion, Devel Biol 139: 89-99.

Eichinger, L., Pachebat, J. A., Glockner, G., Rajandream, M. A., Sucgang, R., Berriman, M., Song, J., Olsen, R., Szafranski, K., Xu, Q., Tunggal, B., Kummerfeld, S., Madera, M., Konfortov, B. A., Rivero, F., Bankier, A. T., Lehmann, R., Hamlin, N., Davies, R., Gaudet, P., Fey, P., Pilcher, K., Chen, G., Saunders, D., Sodergren, E., Davis, P., Kerhornou, A., Nie, X., Hall, N., Anjard, C., Hemphill, L., Bason, N., Farbrother, P., Desany, B., Just, E., Morio, T., Rost, R., Churcher, C., Cooper, J., Haydock, S., van Driessche, N., Cronin, A., Goodhead, I., Muzny, D., Mourier, T., Pain, A., Lu, M., Harper, D., Lindsay, R., Hauser, H., James, K., Quiles, M., Madan Babu, M., Saito, T., Buchrieser, C., Wardroper, A., Felder, M., Thangavelu, M., Johnson, D., Knights, A., Loulseged, H., Mungall, K., Oliver, K., Price, C., Quail, M. A., Urushihara, H., Hernandez, J., Rabbinowitsch, E., Steffen, D., Sanders, M., Ma, J., Kohara, Y., Sharp, S., Simmonds, M., Spiegler, S., Tivey, A., Sugano, S., White, B., Walker, D., Woodward, J., Winckler, T., Tanaka, Y., Shaulsky, G., Schleicher, M., Weinstock, G., Rosenthal, A., Cox, E. C., Chisholm, R. L., Gibbs, R., Loomis, W. F., Platzer, M., Kay, R. R., Williams, J., Dear, P. H., Noegel, A. A., Barrell, B. \& Kuspa, A. (2002). The genome of the social amoeba Dictyostelium discoideum, Nature 435: 43-57.

Erdos, G. W., Raper, K. B. \& Vogen, L. K. (1973). Mating types and macrocyst formation in Dictyostelium discoideum, Proc Natl Acad Sci USA 70:1828-1830.

Filosa, M. F. \& Dengler, R.E. (1972). Ultrastructure of macrocyst formation in the cellular slime mold Dictyostelium mucoroides: Extensive phagocytosis of amoebae by a specialized cell, Dev Biol 29: 1-16.

Filosa, M.F. (1979). Macrocyst formation in the cellular slime mold Dictyostelium mucoroides: Involvement of light and volatile morphogenetic substance(s), J Exp Zool 207: 491-495.

Goff, S. A., Ricke, D., Lan, T. H., Presting, G., Wang, R., Dunn, M., Glazebrook, J., Sessions, A., Oeller, P., Varma, H., Hadley, D., Hutchison, D., Martin, C., Katagiri, F., Lange, B. M., Moughamer, T., Xia, Y., Budworth, P., Zhong, J., Miguel, T.,. Paszkowski, U., Zhang, S., Colbert, M., Sun, W. L., Chen, L., Cooper, B., Park, S., Wood, T. C., Mao, L., Quail, P., Wing, R., Dean, Ryu. Y., Zharkikh, A.,. Shen, R., Sahasrabudhe, S.,A. Thomas, A.,. Cannings, R., Gutin, A., Pruss, D., Reid, J., Tavtigian, S., Mitchell, J., Eldredge, G., Scholl, T., Miller, R. M., Bhatnagar, S., Adey, N., Rubano, T., Tusneem, N., Robinson, R., Feldhaus, J., Macalma, T., Oliphant, A. \& Briggs, S. (2002). A draft sequence of the rice genome (Oryza sativa L. ssp. japonica), Science 296: 92-100.

Gunther, K. E., Ramkisson, H., Lydan, M. A. \& O’Day, D. H. (1995). Fertilization in Dictyostelium discoideum: pharmacological analysis and the presence of a substrate 
protein suggest protein kinase $C$ is essential for gamete fusion, Exp Cell Res 220: 32531.

Howard, P. K., Aher, K. G. \& Firtel, R. A. (1988). Establishment of a transient expression system for Dictyostelium discoideum, Nucleic Acids Research 16: 2613-2633.

Kawai, S., Maeda, Y. \& Amagai, A. (1993). Promotion of zygote formation by protein kinase inhibitors during the sexual development of Dictyostelium mucoroides, Dev Growth Differ 35: 601-607.

Lydan, M. A. \& O'Day, D. H. (1988a). The role of intracellular Ca2+ during early sexual development in Dictyostelium disocideum: effects of $\mathrm{LaCl} 3$, Ins(1,4,5)P3, TMB8, chlortetracycline and A23187 on cell fusion, J Cell Sci 90: 465-473.

Lydan, M. A. \& O'Day, D. H. (1988b). Different developmental functions for calmodulin in Dictyostelium: Trifluoperazine and R24571 both inhibit cell and pronuclear fusion but enhance gamete formation, Exp Cell Res 178: 51-6.

Nickerson, A. W. \& Raper, K. B. (1973). Macrocysts in the life cycle of the Dictyosteliaceae. II. Germination of the macrocyst, Amer J Bot 60: 247-253.

O'Day, D. H. \& Lydan, M. A. (1989). The regulation of membrane fusion during sexual development in Dictyostelium discoideum, Biochem Cell Biol 67: 321-6. Review.

Paterson, B. \& Strohman, R. C. (1972). Myosin synthesis in cultures of differentiating chicken skeletal muscle, Dev Biol 29: 113-138.

Pearson, W. R. (1990). Rapid and sensitive sequence comparison with FASTP and FASTA, Method Enzymol 183: 63-98.

Shainberg, A., Yagil, G. \& Yaffe, D. (1969). Control of myogenesis in vitro by $\mathrm{Ca}^{2+}$ concentration in nutritional medium, Exp Cell Res 58: 163-167.

Shibuya, K., Nagata, M., Tanikawa, N., Yoshioka, T., Hashiba, T. \& Satoh, S. (2002). Comparison of mRNA levels of three ethylene receptors in senescing flowers of carnation (Dianthus caryophyllus), J Exp Bot 53: 399-406.

Suzuki, T., Amagai, A. \& Maeda, Y. (1992). Cyclic AMP and $\mathrm{Ca}^{2+}$ as regulators of zygote formation in the cellular slime mold Dictyostelium mucoroides, Differentiation 49:127-32.

Szabo, S. P., O'Day, D. H. \& Chagla, A. H. (1982). Cell fusion, nuclear fusion, and zygote differentiation during sexual development of Dictyostelium discoideum, Dev Biol 90: 375-82.

Tieman, D. M., Taylor, M. G., Ciardi, J. A. \& Klee, H. J. (2000). The tomato ethylene receptors NR and LeETR4 are negative regulators of ethylene response and exhibit functional compensation within a multigene family, Proc Natl Acad Aci USA 97: 5663-5668.

Yu, J., Hu, S.J. Wang, J., Wong, G. K., Li, S., Liu, B., Deng, Y., Dai, L., Zhou, Y., Zhang, X., Cao, M., Liu, J., Sun, J., Tang, J., Chen, Y., Huang, X., Lin, W., Ye, C., Tong, W., Cong, L., Geng, J., Han, Y., Li, L., Li, W., Hu, G., Li, J., Liu, Z., Qi, Q., Li, T., Wang, X., Lu, H., Wu, T., Zhu, M., Ni, P., Han, H., Dong, W., Ren, X. Feng, X., Cui, P., Li, X., Wang, H., Xu, X., Zhai, W., Xu, Z., Zhang, J., He, S., Xu, J., Zhang, K., Zheng, X., Dong, J., Zeng, W., Tao, L., Ye, J., Tan, J., Chen, X., He, J., Liu, D., Tian, W., Tian, C., Xia, H., Bao, Q., Li, G., Gao, H., Cao, T., Zhao, W., Li, P., Chen, W., Zhang, Y., Hu, J., Liu, S., Yang, J., Zhang, G., Xiong, Y., Li, Z., Mao, L., Zhou, C., Zhu, Z., Chen, R., Hao, B., Zheng, W., Chen, S., Guo, W.,,Tao, M., Zhu, L., Yuan, L., \& Yan, H. (2002). A draftsequence of the rice genome (Oryza sativa L. ssp. indica), Science 296: 79-92. 


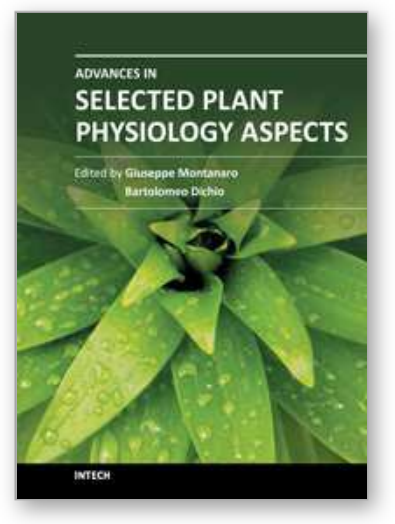

\author{
Advances in Selected Plant Physiology Aspects \\ Edited by Dr. Giuseppe Montanaro
}

ISBN 978-953-51-0557-2

Hard cover, 388 pages

Publisher InTech

Published online 25, April, 2012

Published in print edition April, 2012

The book provides general principles and new insights of some plant physiology aspects covering abiotic stress, plant water relations, mineral nutrition and reproduction. Plant response to reduced water availability and other abiotic stress (e.g. metals) have been analysed through changes in water absorption and transport mechanisms, as well as by molecular and genetic approach. A relatively new aspects of fruit nutrition are presented in order to provide the basis for the improvement of some fruit quality traits. The involvement of hormones, nutritional and proteomic plant profiles together with some structure/function of sexual components have also been addressed. Written by leading scientists from around the world it may serve as source of methods, theories, ideas and tools for students, researchers and experts in that areas of plant physiology.

\title{
How to reference
}

In order to correctly reference this scholarly work, feel free to copy and paste the following:

Aiko Amagai (2012). Regulatory Mechanism in Sexual and Asexual Cycles of Dictyostelium, Advances in Selected Plant Physiology Aspects, Dr. Giuseppe Montanaro (Ed.), ISBN: 978-953-51-0557-2, InTech, Available from: http://www.intechopen.com/books/advances-in-selected-plant-physiology-aspects/induction-ofsexual-cell-fusion-by-ethylene

\section{INTECH}

open science | open minds

\section{InTech Europe}

University Campus STeP Ri

Slavka Krautzeka 83/A

51000 Rijeka, Croatia

Phone: +385 (51) 770447

Fax: +385 (51) 686166

www.intechopen.com

\section{InTech China}

Unit 405, Office Block, Hotel Equatorial Shanghai

No.65, Yan An Road (West), Shanghai, 200040, China

中国上海市延安西路65号上海国际贵都大饭店办公楼405单元

Phone: +86-21-62489820

Fax: $+86-21-62489821$ 
(C) 2012 The Author(s). Licensee IntechOpen. This is an open access article distributed under the terms of the Creative Commons Attribution 3.0 License, which permits unrestricted use, distribution, and reproduction in any medium, provided the original work is properly cited. 